\title{
Seasonal variations in Palaemon serratus abdominal muscle metabolism and performance during exercise, as studied by ${ }^{31}$ P NMR
}

\author{
Marie T. Thebault, Jean P. Raffin \\ Laboratoire de Biologie Marine du Collège de France, BP 225, F-29182 Concarneau Cedex, France
}

\begin{abstract}
Seasonal changes in intracellular $\mathrm{pH}(\mathrm{pHi}$ ) and concentration of ATP, phosphoarginine (Parg) and inorganic phosphate (Pi) were evaluated by ${ }^{31} \mathrm{P}$ Nuclear Magnetic Resonance Spectroscopy (NMR). Nucleotides were extracted from the same individuals and analysed by High Performance Liquid Chromatography (HPLC). In resting prawns in winter, contents of inorganic phosphate and sugar phosphates (SP) increased significantly, but phosphoarginine, ATP, ADP and total adenylate concentration decreased significantly. AMP and IMP tended to increase, but not significantly. The NMR index $($ Parg + Pi $/ \beta A T P+$ Parg + Pi) and the Parg/Pi ratio changed seasonally, unlike the adenylate energy charge. Intracellular $\mathrm{pH}$ was significantly lower in winter, which does not conform to the alphastat hypothesis. At lower temperatures, the prawns exhibited a reduced capacity to be active. At exhaustion, only the content of sugar phosphates and ATP and the intracellular $\mathrm{pH}$ were significantly changed. Recovery of intracellular pH after exhaustion was dependent on season. It is concluded that seasonal variations must be taken into account when studying muscular energy metabolism in ectothermic animals
\end{abstract}

\section{INTRODUCTION}

In ectothermic marine animals, many biological events, particularly motion and muscular activity, are temperature dependent. Metabolic processes are directly affected by external temperature, and animals can adapt to these variations, either by migrating towards more thermostable water, or by varying their metabolism. The latter change can readily be observed at the molecular level (Somero \& Hochachka 1976) and in general corresponds to the re-establishment of homeostasis.

The prawn Palaemon serratus is essentially a sublittoral species widely distributed from Scotland to the north of Morocco. In Brittany (France), during the cold period, older individuals migrate towards deeper water to find more stable conditions, while most younger prawns stay in shore pools where temperatures can fall to 7 or $8^{\circ} \mathrm{C}$ (Richard 1978). Temperatures below $10^{\circ} \mathrm{C}$ markedly influence the behaviour of this prawn: many of its vital activities such as feeding and locomotion are almost totally suspended and growth is interrupted (Cole 1958).
Prawn abdominal muscles are homogeneous and contain almost exclusively fast fibers. They are employed for very quick tail beats during swimming escape behaviour and feeding, propelling the prawn backwards. Burst activity is limited to a few contractions which require a large energy production within a very short time. Thereafter, the prawn is completely exhausted.

The biochemical response of prawns to changes in temperature involves changes of energy production by muscular tissues, the capability for energy production being related to the adenine nucleotide and phosphagen contents of the muscle tissue. Previously, we investigated phosphometabolite changes occurring after vigorous exercise and subsequent recovery in the abdominal musculature of Palaemon serratus (Raffin et al. 1988), using in vivo ${ }^{31} \mathrm{P}$ Nuclear Magnetic Resonance (NMR). This study is concerned with the seasonal variation of energy metabolism and the response of Palaemon serratus of 2 to $3 \mathrm{~cm}$ length to strenuous exercise. We attempt to establish whether there are seasonal differences between prawns collected at various periods of the year in their phosphometabolite 
concentrations, and in their capacity to undergo severe exercise and recovery

\section{MATERIALS AND METHODS}

Prawns. Specimens between 2 and $3 \mathrm{~cm}$ length were collected from the intertidal zone with a small handheld net at low tide and from shallow waters with a prawn-pot at different periods of the year. They were cultured in aerated circulating seawater and fed regularly on chopped mussel.

In the experiments, prawns were placed singly in a small aquarium, and tail flips were elicited by prodding them with a stick. This method has the advantage of inducing the escape behaviour. After each prod, the prawn generally performed a series of a few vigorous tail flips. Continued stimulation led to a further series of tail flips that became progressively less powerful, until ultimately there was no response to the stimuli (exhaustion). The ability to exercise was estimated by counting the tail flips leading to exhaustion. Immediately after exhaustion, the prawn was placed in a $10 \mathrm{~mm}$ (i.d.) NMR cone-shaped tube containing recirculating aerated seawater thermoregulated at the temperature of collection $\left(T \pm 1^{\circ} \mathrm{C}\right)$. Prawns were allowed to recover in the NMR probe, or were freezeclamped before biochemical extraction.

In addition to the exercise protocol, duplicate NMR measurements were made before, or at least $1 \mathrm{~h}$ after, the exercise bout. Since muscle metabolites were affected by exercise, the prawns were immobilized in the NMR probe for at least $10 \mathrm{~min}$. A series of control prawns were freeze-clamped. Those showing spontaneous escape reactions were excluded.

Materials. Nucleotides and tri-n-octylamine were purchased from Sigma Chemical Co. (St. Louis, MO, USA). 1,1,2-trichloro-trifluoro-ethane (freon) was obtained from Riedel-de Haën AG (Seelze, Germany). All other chemicals were analytical grade reagents from Merck (Darmstadt, Germany) or Carlo Erba (Milano, Italy).

NMR measurements. Phosphorus NMR spectra were generated at $40.32 \mathrm{MHz}$ in pulsed Fourier transform mode on a Jeol FX 100Q spectrometer with an internal ${ }^{2} \mathrm{H}$ lock $\left(\mathrm{D}_{2} \mathrm{O}\right)$ for field frequency stabilization. Each spectrum consisted of 200 data acquisitions accumulated with a delay time of $3.0 \mathrm{~s}$, a tip angle of $72^{\circ}$ (pulse width: $60 \mu \mathrm{s}$ ) and a sweep width of $2500 \mathrm{~Hz}$. Saturation factors, described by Dawson et al. (1977), were obtained as previously described (Thébault et al. 1987). The saturation factor is 1.0 for phosphoarginine, sugar phosphates and ATP, and 1.31 for inorganic phosphate. As internal reference we used a known quantity of $85 \%$ orthophosphoric acid diluted in $\mathrm{D}_{2} \mathrm{O}$ and isolated from the sample by sealing it in a plastic capillary tube coaxially mounted in the NMR tube along with the sample under study. The relative concentration, expressed as ${ }^{31} \mathrm{P}$ magnetization units (MU) of inorganic phosphate, phosphoarginine, ATP and sugar phosphates, was determined by peak area integration of the respective resonances. Intracellular $\mathrm{pH}$ (pHi) was estimated from the chemical shifts of inorganic phosphate as previously described (Thébault et al. 1987). The temperature dependence of the dissociation constant (pKa) of inorganic phosphate was taken into account. A $10^{\circ} \mathrm{C}$ variation of temperature resulted in a pH shift of 0.030 units in the physiological range.

Metabolite assays. Tails were removed rapidly, and freeze-clamped in liquid nitrogen. The frozen muscle was dissected free of cuticle and divided into 2 parts, one dried at $60^{\circ} \mathrm{C}$ for $2 \mathrm{~d}$ for the determination of dry weight, the other homogenized under liquid nitrogen in 6 volumes of $12 \%(\mathrm{w} / \mathrm{v})$ trichloroacetic acid. Homogenates were centrifuged at $31000 \times g$ for 15 min at $4{ }^{\circ} \mathrm{C}$ and the supernatants were extracted by the amine-freon procedure as described by Khym (1975) and modified by Chen et al. (1977). The samples were stored at $-80^{\circ} \mathrm{C}$ until HPLC analysis.

High Performance Liquid Chromatography analysis. The HPLC system was a LKB model 2150 equipped with a Uvicord SD detector and a data acquisition system consisting of an analog-digital interface linked to an IBM-PC computer and a control program written in Turbo-Basic. Peak integration was performed using the method of the mean parabola with a program written in Turbo-Pascal. The HPLC column was a Whatman Partisphere SAX (12.5 cm $\times 4.6 \mathrm{~mm}$ i.d.) with a particle size of $5 \mu \mathrm{m}$. Aliquots of $20 \mu \mathrm{l}$ sample solutes were injected. The flow-rate was $1 \mathrm{ml} \mathrm{m^{-1 }}$ and the mobile phase used for the separation consisted of 2 eluants: $0.01 \mathrm{M}$ potassium dihydrogen phosphate solution titrated to $\mathrm{pH} 3.5$ with $85 \%$ phosphoric acid (buffer $\mathrm{A}$ ), and $0.75 \mathrm{M} \mathrm{KH}_{2} \mathrm{PO}_{4}$ solution titrated to $\mathrm{pH}$ 5.0 with $10 \mathrm{~N} \mathrm{KOH}$ (buffer $\mathrm{B}$ )

The chromatographic conditions used were $6 \mathrm{~min}$ at $100 \%$ of buffer A, 10 min up to $11 \%$ of buffer B, 5 min at $11 \%$ of buffer $\mathrm{B}, 3 \mathrm{~min}$ up to $15 \%$ of buffer $\mathrm{B}, 11 \mathrm{~min}$ at $15 \%$ of buffer $B, 25$ min up to $100 \%$ of buffer $B$ and $40 \mathrm{~min}$ at $100 \%$ of buffer $A$ to reach the initial conditions. The analyses were performed at room temperature and the UV detector was operated at $254 \mathrm{~nm}$.

Quantitative measurements were carried out by injection of standard solutions of known concentrations. The standard solutions were calibrated at $260 \mathrm{~nm}$ and $\mathrm{pH} 7.0$ using the following extinction values: $15.37 \mathrm{mM}$ for adenosine triphosphate (ATP), adenosine diphosphate (ADP) and adenosine monophosphate (AMP), $12.19 \mathrm{mM}$ for guanosine triphosphate (GTP), $6.88 \mathrm{mM}$ for inosine monophosphate 
(IMP), $9.98 \mathrm{mM}$ for uridine triphosphate (UTP) and $7.43 \mathrm{mM}$ for cytidine triphosphate (CTP), which were the major nucleotides detected in the extracts.

Physiological parameters.

Adenylate energy charge (AEC):

$$
\frac{\mathrm{ATP}+1 / 2 \mathrm{ADP}}{\mathrm{ATP}+\mathrm{ADP}+\mathrm{AMP}}
$$

as defined by Atkinson (1977), is considered to be a regulator of anabolic and catabolic processes.

Adenylate sum ( $\Sigma A)$ : ATP + ADP + AMP: indicates the degradation of the adenylate pool.

Adenylate sum + IMP $(\Sigma A+I M P)$ : takes into account the AMP deaminase reaction which produces IMP from AMP during exercise in vertebrate muscle.

BATP: ATP measured by the NMR technique (corresponds to the $\beta$ resonance peak of ATP).

NMR index: (described by Lavanchy et al. 1985) is defined as the amount of energy available to an organism from the phosphagen and the ATP pools. It is calculated by the formula:

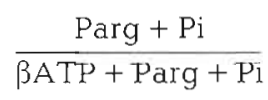

Statistical methods. Differences between means were tested using the the non-parametric test of Mann and Whitney. Prawns were classified into 2 groups: June to September as 'warm' and January to March as 'cold' treatments, after careful analysis of the probability distribution of the experimental specimens using the Rankit method.

\section{RESULTS}

\section{Seasonal variations of temperature}

As an example, annual seawater temperature variation in the intertidal zone in the Bay of Concarneau was determined in 1987 . The lower value observed was $7^{\circ} \mathrm{C}$ in February and March, while the upper value was $17.5^{\circ} \mathrm{C}$ in September (Fig. 1).

\section{Seasonal variations of muscle metabolism at rest}

Phosphometabolite levels. The main features of ${ }^{31} \mathrm{P}$ NMR spectra of tail muscle were discussed in detail in a previous paper (Raffin et al. 1988). At rest, sugar phosphates and inorganic phosphate appear as small signals, while the major resonances are phosphoarginine and the $\tau, \alpha$ and $\beta$ groups of ATP.

The relative concentrations of phosphometabolites in tail muscle were measured by ${ }^{31} \mathrm{P} N M R$ in resting

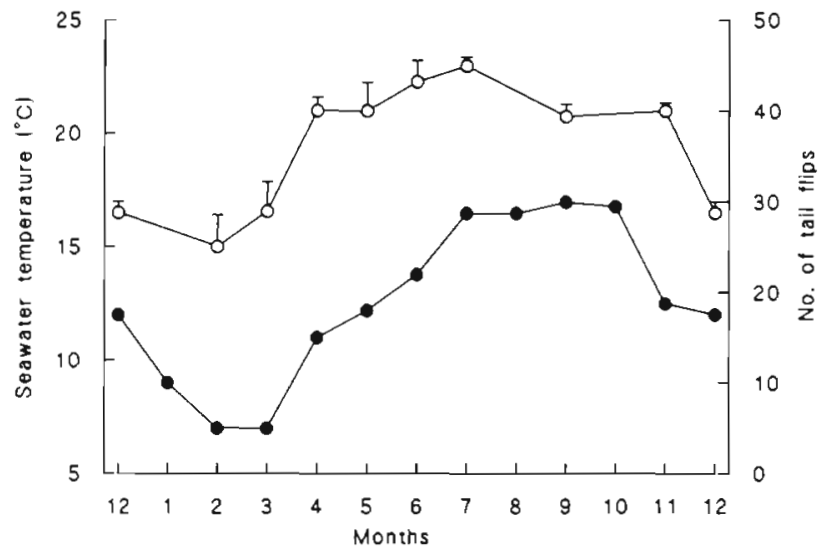

Fig. 1 Seasonal variation of seawater temperature $(\bullet)$ in the intertidal zone, bay of Concarneau, and of number of tail flips of Palaemon sersatus leading to complete exhaustion (o). For tail flips, each value is mean $\pm \operatorname{SEM}(n=4)$

prawns during the cold and warm periods of the year (Table 1). When winter and summer prawns were compared by the Mann-Whitney test, the levels of $\beta$ ATP and phosphoarginine were found to be significantly lower in winter $(\alpha \leq 0.01$ and $\alpha \leq 0.05$ respectively), while inorganic phosphate and the sugar phosphate contents were increased $(\alpha \leq 0.01$ and $\alpha \leq 0.05$ respectively) within this period.

ATP, measured after biochemical extraction and HPLC analysis, likewise decreased in winter. This was

Table 1 Palaemon serratus. Concentrations of phosphometabolites in the abdominal muscle of resting prawns, during the warm period (June to September) and the cold period (January to March). The relative concentrations of inorganic phosphate (Pi), phosphoarginine (Parg), sugar phosphates (SP) and BATP were calculated from the ${ }^{11} \mathrm{P}$ NMR peak areas corrected by the saturation factors. Absolute concentrations of ATP, ADP, AMP, IMP, GTP, UTP and CTP were calculated after biochemical extraction and HPLC analysis and are expressed as $\mu \mathrm{mol} \mathrm{g}^{-1}$ dry weight. Values are means $\pm \mathrm{SD}$. Significant differences $\left({ }^{\circ} \alpha \leq 0.05 ; \cdots \alpha \leq 0.01\right)$ were tested using the non-parametric test of Mann and Whitney ( $\mathrm{n}=9$ in winter and 21 in summer)

\begin{tabular}{|llll|}
\hline & & Warm period & Cold period \\
\hline NMR & Pi & $0.142 \pm 0.002$ & $0.238 \pm 0.021^{\circ}$ \\
data & Parg & $0.391 \pm 0.016$ & $0.323 \pm 0.023^{\circ}$ \\
& SP & $0.021 \pm 0.005$ & $0.043 \pm 0.009^{\circ}$ \\
& BATP & $0.136 \pm 0.008$ & $0.104 \pm 0.008^{\circ}$ \\
HPLC & ATP & $8.640 \pm 2.190$ & $6.512 \pm 2.748^{\circ}$ \\
data & ADP & $1.543 \pm 0.463$ & $1.015 \pm 0.264^{\circ}$ \\
& AMP & $0.195 \pm 0.178$ & $0.329 \pm 0.380^{\circ}$ \\
& IMP & $0.070 \pm 0.068$ & $0.149 \pm 0.174$ \\
& GTP & $0.140 \pm 0.044$ & $0.097 \pm 0.062$ \\
& UTP & $0.224 \pm 0.091$ & $0.155 \pm 0.076$ \\
& CTP & $0.113 \pm 0.040$ & $0.071 \pm 0.044^{\circ}$ \\
\hline
\end{tabular}


accompanied by a concomitant decrease of ADP. while AMP and IMP increased (Table 1). However, the Mann-Whitney test showed significance only for ADP.

Physiological parameters. Several energetic parameters can be calculated from a single NMR spectrum.

The NMR index and the Parg/Pi ratio (Table 2) were found to be significantly higher in summer $(\alpha \leq 0.01)$. In contrast, the Pi/ $\beta A T P$ ratio was ca $40 \%$ lower in summer $(\alpha \leq 0.01)$, while the Parg/ $\beta$ ATP ratio and the sums $($ Parg + Pi) and (Parg + Pi + BATP) did not show significant seasonal variations (Table 2 ).

Some physiological parameters were calculated from HPLC results (Table 2). The total adenylate concentration (ATP + ADP + AMP) decreased significantly in winter. On the other hand, the ATP/ADP ratio and the adenylic energy charge were not significantly different (Table 2).

Intracellular $\mathrm{pH}$. The value of $\mathrm{pHi}$, calculated from ${ }^{31} \mathrm{P}$ NMR spectra, was significantly higher $(\alpha \leq 0.01)$ in summer $(\mathrm{pHi}=7.33 \pm 0.01)$ than in winter $(\mathrm{pHi}=7.13$ \pm 0.04 ) in the abdominal muscle of resting prawns.

As shown in Fig. 2, the intracellular $\mathrm{pH}$ increases with environmental temperature. However, above $17^{\circ} \mathrm{C}$, which can be considered as a sublethal temperature, the pHi fell again.

\section{Capacity for strenuous muscular activity}

Prawns exercised to exhaustion exhibited a series of 10 to 40 rapid and powerful tail flips, followed by a

Table 2. Palaemon serratus. Seasonal variation of some physiological parameters from the abdominal muscle of resting prawns, during the warm period (June to September) and the cold period (January to March). NMR parameters were calculated from the ${ }^{3 i} \mathrm{P}$ NMR relative concentrations of phosphometabolites. Biochemical parameters were calculated from the absolute concentrations of phosphometabolites measured after biochemical extraction and HPLC analysis and are expressed as $\mu \mathrm{mol} \mathrm{g}^{-1}$ dry weight. Values are means \pm SD. Significant differences ( $\alpha \leq 0.05{ }^{*} \cdot \alpha \leq 0.01$ ) were calculated by the non-parametric test of Mann and Whitney ( $n=9$ in winter and 21 in summer)

\begin{tabular}{|c|c|c|c|}
\hline & & Warm period & Cold period \\
\hline $\begin{array}{l}\text { NMR } \\
\text { data }\end{array}$ & 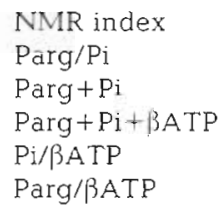 & $\begin{array}{l}0.791 \pm 0.025 \\
3.701 \pm 0.593 \\
0.533 \pm 0.011 \\
0.670 \pm 0.013 \\
1.381 \pm 0.364 \\
3667 \pm 0.874\end{array}$ & $\begin{array}{l}0.641 \pm 0.031 \cdots \\
1.527 \pm 0.212 \cdots \\
0.561 \pm 0.011 \\
0.671 \pm 0.010 \\
2.449 \pm 0.294 \cdots \\
3.308 \pm 0.351\end{array}$ \\
\hline $\begin{array}{l}\text { HPLC } \\
\text { data }\end{array}$ & $\begin{array}{l}\sum A \\
\sum A+I M P \\
A T P / A D P \\
A E C\end{array}$ & $\begin{array}{r}10.378 \pm 2.544 \\
10448 \pm 2.575 \\
5.789 \pm 1.342 \\
0.907 \pm 0.027\end{array}$ & $\begin{array}{l}7.856 \pm 2.557^{\circ} \\
8.005 \pm 2.523^{\circ} \\
6.822 \pm 2.865 \\
0.878 \pm 0.100\end{array}$ \\
\hline
\end{tabular}

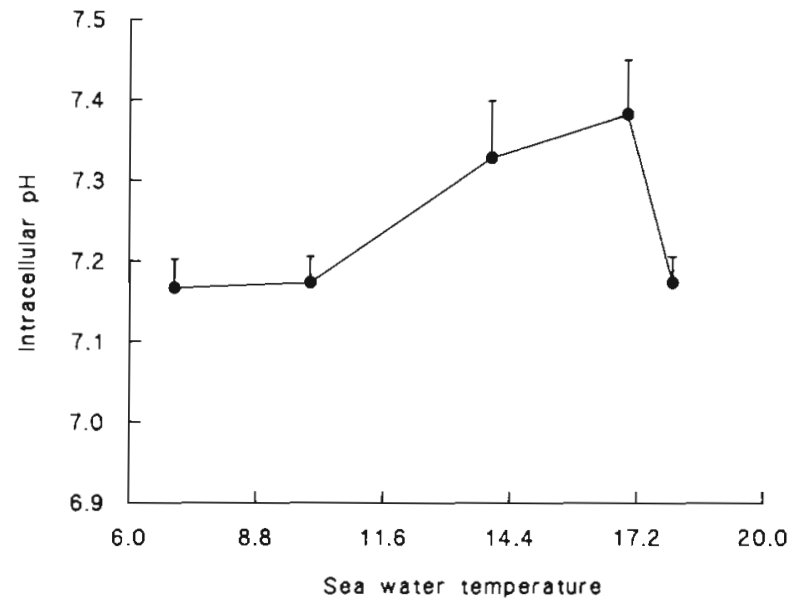

Fig. 2. Palaemon serratus. Intracellular $\mathrm{pH}$ as a function of seawater temperature. Values are means \pm SEM $(n=4$ to 12 , depending on temperature)

further series of 5 to 10 slower and less powerful tail flips until the prawns appeared exhausted. The second stage was characterized by a change in the colour of the abdominal muscles, which became whitish.

The number of tail flips leading to complete exhaustion was related to seasonal changes (Fig. 1). Prawns collected during winter showed less ability to exercise compared to those collected during summer. Furthermore, a substantial proportion of the 'winter' prawns died within a few hours of exhaustion, especially in February and March. A temperature of $10^{\circ} \mathrm{C}$ was found to mark the limit between the 2 kinds of exhaustion behaviour.

\section{Seasonal variations of muscle metabolism in exhausted prawns}

Phosphometabolite levels. Large changes in phosphometabolite levels occurred after exhaustive exercise, as previously described (Raffin et al. 1988). ${ }^{31} \mathrm{P}$ NMR spectra revealed elevated inorganic phosphate and sugar phosphate levels, while phosphoarginine was considerably depleted. Concomitantly, the biochemical analysis revealed a breakdown of ATP, but no change in the total adenylate concentration, resulting in a dramatic drop in the adenylate energy charge (Raffin \& Thébault unpubl.).

Relative phosphometabolite concentrations in abdominal muscle were measured by ${ }^{31} \mathrm{P} N \mathrm{NMR}$ in exhausted prawns (Table 3). When 'winter' and 'summer' prawns were compared by the Mann-Whitney test, levels of inorganic phosphate and phosphoarginine were not significantly different, but the sugar phosphate and ATP contents were ca $50 \%$ higher and 
Table 3. Palaemon serratus. Concentrations of phosphometabolites in the abdominal muscle of exhausted prawns during the warm period (June to September) and the cold period (January to March). Relative concentrations of inorganic phosphate, phosphoarginine, sugar phosphates and BATP were calculated from the ${ }^{31} \mathrm{P}$ NMR peaks areas corrected by the saturation factors. Absolute concentrations of ATP, ADP, AMP, IMP, GTP, UTP and CTP were calculated after biochemical extraction and HPLC analysis and are expressed as $\mu \mathrm{mol} \mathrm{\textrm {g } ^ { - 1 }}$ dry weight. Values are means $\pm \mathrm{SD}$. Significant differences ( $\alpha \leq 0.05 ; \cdots \alpha \leq 0.01)$ calculated by the non-parametric test of Mann and Whitney ( $n=19$ in winter and 12 in summer]

\begin{tabular}{|llll|}
\hline & & Warm period & Cold period \\
\hline NMR & Pi & $0.349 \pm 0.038$ & $0.394 \pm 0.028$ \\
data & Parg & $0.198 \pm 0.027$ & $0.190 \pm 0.018$ \\
& SP & $0.049 \pm 0.012$ & $0.085 \pm 0.015^{\circ}$ \\
& BATP & $0.129 \pm 0.007$ & $0.102 \pm 0.006^{\circ}$ \\
HPLC & ATP & $2.834 \pm 1.283$ & $2.210 \pm 1.665$ \\
data & ADP & $3.011 \pm 0.966$ & $2.367 \pm 0.940$ \\
& AMP & $2.994 \pm 1.575$ & $2.821 \pm 1.450$ \\
& IMP & $0.220 \pm 0.322$ & $0.340 \pm 0.657$ \\
& GTP & $0.078 \pm 0.043$ & $0.064 \pm 0.044$ \\
& UTP & $0.161 \pm 0.075$ & $0.102 \pm 0.051$ \\
& CTP & $0.216 \pm 0.347$ & $0.068 \pm 0.041$ \\
& & & \\
\hline
\end{tabular}

$25 \%$ lower respectively in winter $(\alpha \leq 0.05)$. Moreover, phosphometabolite changes occurring in response to vigorous exercise were smaller during the cold period (Table 3).

ATP measured after biochemical extraction and HPLC analysis decreased similarly in winter. Even though the differences were not statistically significant, the level of ADP had a tendency to decrease in coldexposed prawns (Table 3 ).

Variations of the phosphometabolites as a consequence of exhausting exercise were generally lower in winter, except for ADP which showed a higher increase in winter (Fig. 3).

Physiological parameters. NMR index, Parg/Pi, Pi/ BATP, Parg/BATP, (Parg + Pi) and (Parg + Pi + $\beta$ ATP $)$ did not change significantly over the year in exhausted prawns (Table 4). Similarly, the biochemical parameters were not influenced by the season.

Intracellular $\mathrm{pH}$. The value of intracellular $\mathrm{pH}$ in the abdominal muscle of exhausted prawns was significantly higher $(\alpha \pm 0.05)$ in summer $(\mathrm{pHi}=7.14 \pm 0.05)$ than in winter $(\mathrm{pHi}=7.02 \pm 0.03)$.

\section{Seasonal capacity for recovery from exhaustive work}

Recovery of phosphometabolite levels. In winter, no significant recovery of ATP, inorganic phosphate and

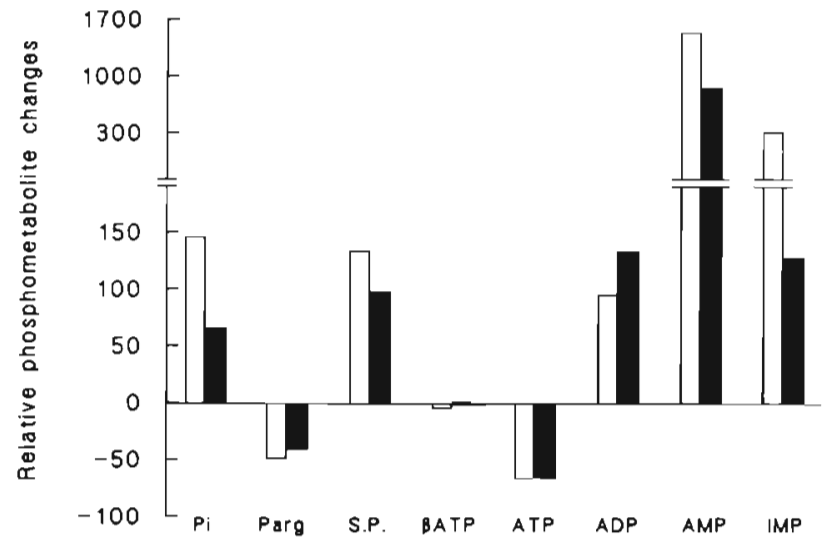

Fig. 3. Palaemon serratus. Relative phosphometabolite changes as a consequence of exercise in summer (open bars) and winter (black bars). Relative concentrations of $\mathrm{Pi}, \mathrm{Parg}$, S.P. and BATP, measured by NMR, are expressed as ${ }^{31} \mathrm{P}$ magnetization units (see 'Materials and methods'). Absolute concentrations of ATP, ADP, AMP and IMP, determined by HPLC, are expressed as $\mu \mathrm{mol} \mathrm{g}^{-1}$ dry weight

phosphoarginine levels occurred during the time course of the experiment (Fig. 4A).

In summer, the decrease of the inorganic phosphate concentration was balanced by a net increase of phosphoarginine (Fig. 4B). Since $\beta$ ATP changes during exercise were very low (Tables 1 and 3), the ATP level remained unchanged during recovery from exercise.

Recovery of physiological parameters. No significant recovery of the NMR indexes occurred in winter

Table 4. Palaemon serratus. Seasonal variation of some phy. siological parameters from the abdominal muscle of exhausted prawns, during the warm period (June to September) and the cold period (January to March). NMR parameters were calculated from the ${ }^{31} \mathrm{P}$ NMR relative concentrations of phosphometabolites. Biochemical parameters were calculated from the absolute concentrations of phosphometabolites measured after biochemical extraction and HPLC analysis and are expressed as $\mu \mathrm{mol} \mathrm{g}^{-1}$ dry weight. Values are means \pm SD. Significant differences were calculated by the non-parametric test of Mann and Whitney ( $\mathrm{n}=19$ in winter and 12 in summer)

\begin{tabular}{|c|c|c|c|}
\hline & & Warm period & Cold period \\
\hline NMR & NMR index & $0.484 \pm 0.052$ & $0.429 \pm 0.033$ \\
\hline \multirow[t]{5}{*}{ data } & $\mathrm{Parg} / \mathrm{Pi}$ & $0.698 \pm 0.221$ & $0.537 \pm 0.083$ \\
\hline & Parg $+\mathrm{Pi}$ & $0.546 \pm 0.019$ & $0.583 \pm 0.019$ \\
\hline & Parg $+P i+B A T P$ & $0.672 \pm 0.015$ & $0.685 \pm 0.017$ \\
\hline & PI/ßATP & $3.100 \pm 0.566$ & $4.081 \pm 0.455$ \\
\hline & Parg/ßATP & $1.682 \pm 0.628$ & $1.855 \pm 0.149$ \\
\hline HPLC & $\Sigma \mathrm{A}$ & $8.839 \pm 2.657$ & $7.398 \pm 2.381$ \\
\hline \multirow[t]{3}{*}{ data } & $\Sigma A+I M P$ & $9.059 \pm 2.869$ & $7.738 \pm 2.604$ \\
\hline & ATP/ADP & $0.991 \pm 0.508$ & $0.900 \pm 0.681$ \\
\hline & $\mathrm{AEC}$ & $0.498 \pm 0.118$ & $0.438 \pm 0.185$ \\
\hline
\end{tabular}




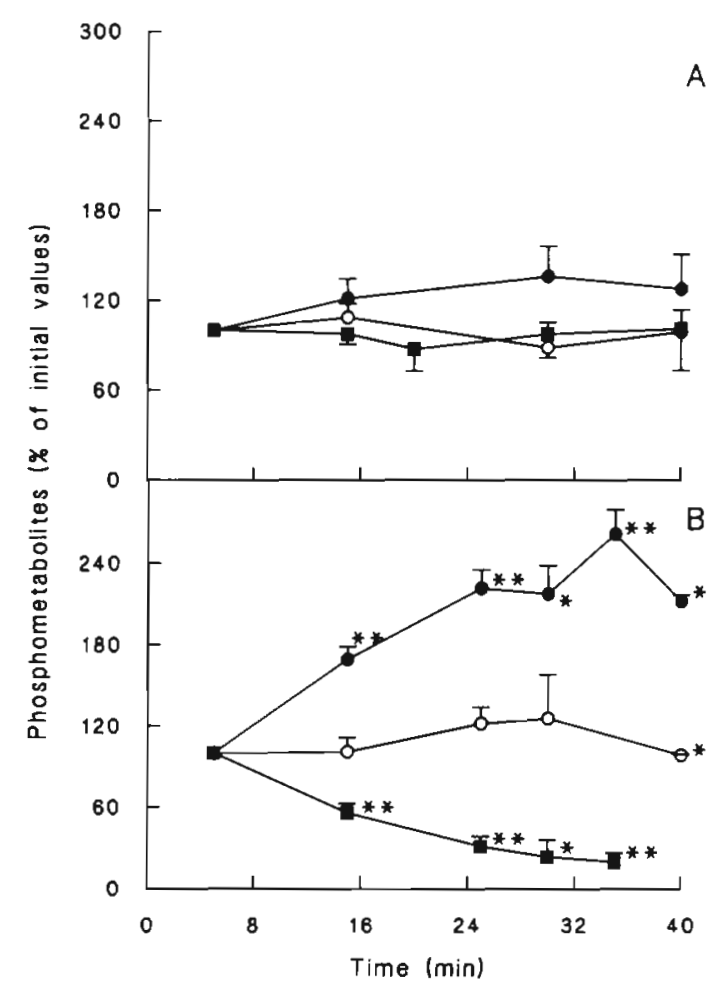

Fig. 4. Palaemon serratus. Restoration of phosphometabolite from exhaustive exercise in abdominal muscles in (A) winter and $(B)$ summer Values are means $\pm \operatorname{SEM}(\mathrm{n}=2$ to 15 , depending on time) of phosphoarginine ( $\bullet$ ). inorganic phosphate (1) and BATP (O), of the relative concentrations from NMR spectra, in percent of initial values (data obtained at the end of muscular stimulation). Significant differences $(\cdot \alpha \leq 0.05 ; \cdots \alpha \leq 0.01)$ were calculated by the non-parametric test of Mann and Whitney

(Fig. 5A). On the contrary, in summer, recovery began immediately (Fig. 5B).

Intracellular $\mathrm{pH}$ restoration. In winter, the intracellular $\mathrm{pH}$ decreased significantly (Mann-Whitney test, $\alpha \leq 0.05$ ) during 25 min of recovery from vigorous exercise. In summer, the pHi increase occurred 15 min after exhaustion. The pHi did not normalize within 35 min of recovery (Fig. 6)

\section{DISCUSSION}

Although it is not a completely quantitative procedure, ${ }^{31}$ P NMR has emerged as a novel method for the non-invasive study of muscle metabolism. Prawns examined by ${ }^{31} \mathrm{P}$ NMR were further freeze-clamped for biochemical extraction of phosphometabolites. Results from ${ }^{31} \mathrm{P}$ NMR were in good agreement with those from biochemical procedures. Values from NMR experiments showed less variation, resulting from the simplicity of the manipulation.

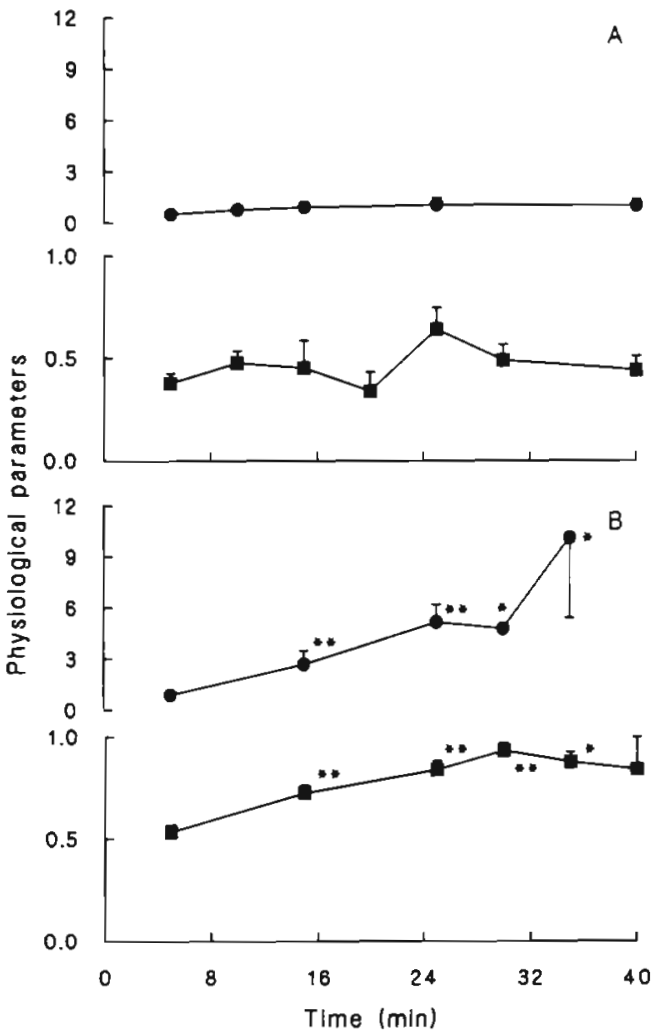

Fig. 5. Palaemon serratus. Restoration of NMR indexes from exhaustive exercise in abdominal muscles in (A) winter and (B) summer Values are means $\pm \operatorname{SEM}(\mathrm{n}=2$ to 15 , depending on time) for the Lavanchy index (-) and Parg/Pi (•). Significant differences ( $\alpha \leq 0.05 ; \cdots \alpha \leq 0.01$ ) were calculated by the non-parametric test of Mann and Whitney

\section{Seasonal metabolite changes in resting prawns}

In resting prawns, the $40 \%$ increase of inorganic phosphate in winter was balanced by the concomitant reductions of phosphoarginine $(17 \%)$ and ATP $(23 \%)$. The large increase of sugar phosphates in winter $(50 \%)$ indicates an elevated rate of glycolysis. In winter, the increase of AMP and IMP, related to the concomitant total adenylate concentration decrease, shows a larger nucleotide degradation during the cold period. Low temperatures were found to affect vertebrate muscles similarly. in frog gastrocnemius muscle (Ohira \& Ohira 1988), the content of ATP decreased after cold exposure, this decrease being greater in starved individuals.

High individual variations in phosphometabolite concentration were associated with higher values of standard deviation, especially in winter and in exhausted prawns. The variability was greatest for AMP and IMP, probably because these metabolites are present in much lower concentrations than ATP and 
ADP. Many studies have found that levels of variability are greater under field conditions than under laboratory conditions (Giesy \& Dickson 1981). However, individual variability in energy metabolism is due, at least in part, to genotype. High genetic heterozygosity is correlated with low maintenance energy cost (Koehn \& Bayne 1989). Hence, temperature and exercise should enhance differences between individuals in genotypedependent metabolites.

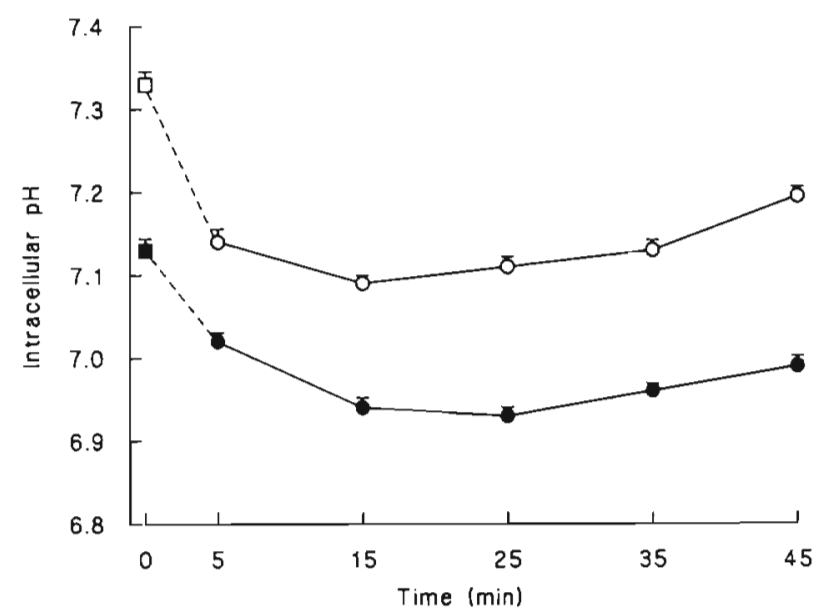

Fig. 6. Palaemon serratus. Intracellular $\mathrm{pH}$ recovery after exhaustive work in abdominal muscles in summer (o) and winter (-). Values are means $\pm \operatorname{SEM}(n=8$ in winter and 10 in summer). $t=0(\square, \square)$ corresponds to the data obtained at rest and $t=5$ to the data obtained at the end of muscular stimulation

\section{Seasonal physiological parameter changes in resting prawns}

The large decrease of adenylates in winter could be related to reproduction state, as shown by Giesy \& Dickson (1981) for molluscs. Palaemon serratus exhibited minimum values of adenylates in February and March, which could be expected to be the period of maximum reproduction for 2 to $3 \mathrm{~cm}$ length prawns. Concomitantly, a growth decrease was observed during breeding. However, within this period, the seawater temperature was low (below $8^{\circ} \mathrm{C}$ ), and prawns ceased feeding and active swimming. Starvation was an important factor concerning seasonal variations in metabolism. Temperature is inversely correlated with storage processes in the crayfish (Collatz 1973), a temperature of $12^{\circ} \mathrm{C}$ being characteristic for the beginning of storage occurring prior to moulting. Atkinson (1977) described the adenylate energy charge as a key ratio involved in the regulation of energy transfer through catabolic and anabolic enzyme systems. This ratio rep- resents the internal energy status of the cell, from which the condition of the organism can be estimated (Chapman et al. 1971). High values (between 0.8 and $0.9)$ have generally been found in organisms in a nonlimiting environment. In $P$. serratus abdominal muscle, the large decrease of adenylates in winter was not associated with any change in the adenylate energy charge. AMP deaminase, which deaminates AMP to IMP, is known to be the enzyme which maintains the adenylate energy charge during limiting conditions. Although there was a small amount of AMP deaminase in $P$. serratus abdominal muscle (Raffin \& Thébault 1987), it was sufficient to allow the maintenance of the adenylate energy charge at rest when environmental temperature stress occurs. The action of AMP deaminase, i.e. the removal of AMP, leads to a depletion of adenylate nucleotides.

Adenylate energy charge and total adenylate pool are relatively independent and organisms adjust adenylate concentrations and rates of catabolism to maintain a constant adenylate energy charge. Furthermore, a low level of variability was found, when compared with adenylate absolute concentrations. In addition to metabolic regulation of the adenylate energy charge, variations are damped, relative to individual adenylate concentrations, because the adenylate energy charge is a ratio. Therefore, the adenylate energy charge is a highly regulated parameter and physiological response to limiting conditions should be much better monitored by using the size of the adenylate pool or, better, the very sensitive NMR indexes.

The stability of the ATP/ADP ratio is related to the stability of the energy charge (Reed 1976), and this relation is dependent on the adenylate kinase equilibrium (Raffin \& Thébault unpubl.). The concomitant stability of the Parg/ATP ratio shows the stability of the arginine kinase equilibrium constant through the year. The ATP/ADP ratio is considered to reflect the metabolic state of the cell. In Palaemon serratus muscle, it was not affected by the cold, since ATP and ADP were similarly reduced in winter.

Several energetic parameters can be calculated from a single NMR spectrum, which can be used to evaluate energetic changes under natural environmental fluctuations. By definition, the NMR index has a specific range of values from 0 to 1 . The index generally falls into one of 3 ranges, which are characteristic for: optimal conditions ( 0.8 to 1$)$, limiting conditions $(0.5$ to 0.8$)$ and stressful conditions (0.5) (Thébault \& Raffin 1989). In winter, the NMR index shows that prawns are submitted to limiting conditions. The alterations of Parg/Pi and Pi/BATP are caused by the great increase of Pi and the decrease of ATP during the cold period. The ratio Parg/Pi is a very sensitive index of the energetic state of working muscle. The ratio Pi/ $\beta A T P$ can also be consid- 
ered as a suitable index for the estimation of muscular stress. There was no variation of the sums Parg $+\mathrm{Pi}$ and Parg $+\mathrm{Pi}+\beta A T P$, which indicates that the increase of inorganic phosphate is related to the decrease of phosphoarginine and ATP.

\section{Seasonal intracellular $\mathrm{pH}$ changes in resting prawns}

Body temperature is a key factor in determining the intracellular acid-base state in ectothermic species. ${ }^{31} \mathrm{P}$ NMR is considered as a reliable method for estimation of the intracellular $\mathrm{pH}$, and values are in good agreement with those obtained with other methods. The slight increase in alkalinity with higher temperature points to an unusual acid-base regulation, which does not conform to that predicted by the alphastat hypothesis (Malan et al. 1976). Recent studies have shown that a number of species show significant departures from this hypothesis, especially fish (Heisler et al. 1976. Walsh \& Moon 1982, Johnston et al. 1983). The pHi decrease in winter, correlated with the sugar phosphate increase, indicates a higher rate of glycolysis in response to cold, as shown by Blomstrand \& EssénGustavsson (1987) in humans. Under such conditions of decrease in temperature and $\mathrm{pHi}$, a substantial metabolic deactivation occurs and animals cease feeding and remain inactive.

\section{Seasonal changes of activity in Palaemon serratus}

Seasonal and daily activity periods in Palaemon serratus are limited to some extent by environmental temperatures; the minimum activity temperature is below $10^{\circ} \mathrm{C}$. Improvements in muscular performance are shown from April $\left(11^{\circ} \mathrm{C}\right)$ to November $\left(12^{\circ} \mathrm{C}\right)$. In contrast, in February and March, when the seawater temperature falls below $8^{\circ} \mathrm{C}$, many prawns die after exercise.

Temperature changes influence neuromuscular transmission (Stephens 1985), which may influence neurons that secrete hormones having a modulatory effect on neuromuscular transmission (Jacobs \& Atwood 1981). Possibly, temperature could affect neuromuscular transmission in Palaemon serratus tail muscles, since winter prawns warmed above $10^{\circ} \mathrm{C}$ quickly began to move about.

A detailed analysis of the walking rate of lobster, in relation to acclimation and test temperatures, is described by Alderdice (1972). The catchability of lobster is related to temperature (McLeese \& Wilder 1958) and, in winter, they could not be captured using a prawn-pot. Palaemon serratus shows a similar behaviour

\section{Seasonal phosphometabolite and physiological parameter changes in exercised prawns}

During exercise, inorganic phosphate, sugar phosphates, ADP, AMP and IMP increase, while phosphoarginine and ATP decrease drastically (Raffin et al. 1988) in summer and in winter. However, whereas in resting prawns Parg, Pi and adenylate concentrations vary significantly over the year, in exhausted prawns these phosphate variations are less pronounced. Only sugar phosphate and ATP concentrations were found to increase and decrease respectively in winter when compared to summer. On the other hand, variations of ADP and IMP were lower than in resting prawns.

Thus, environmental temperature has little effect on the mechanism of muscle fatigue. In addition, since the relative metabolite changes between rest and exercise are higher in summer than in winter, the better exercise performance measured in summer is related to the higher energy stores available.

Likewise, at the end of exercise, the physiological parameters are similar in winter and in summer. Therefore, season affects the exercise performance but not the mechanism leading to fatigue.

\section{Seasonal intracellular $\mathrm{pH}$ changes in exercised prawns}

The intracellular $\mathrm{pH}$ decrease is considered to be an important factor in the development of muscular fatigue (Sahlin et al, 1983). In addition, studies of Blomstrand \& Essén-Gustavson (1987) have shown that moderate cooling of the human muscle influenced muscle performance, and was accompanied by an increase in the rate of glycolysis from glycogen.

In Palaemon serratus tail muscle, concomitantly with acidification of the intracellular $\mathrm{pH}$ in winter, there is a decrease in the ability of the muscle to perform work. However, the degree of acidification as a result of muscle contraction was the same in winter and summer. Therefore, the better exercise performance of summer prawns is not related to a greater change of $\mathrm{pHi}$, but could nevertheless depend on the absolute pHi.

This must be related to the net phosphometabolite and sugar phosphate changes during exercise. Contrary to the intracellular $\mathrm{pH}$, the magnitude of these changes is seasonally dependent. Thus, the activation of glycolysis is related neither to the net phosphometabolite changes, nor to the energetic state at the onset of exercise. 


\section{Recovery from muscular activity as a function of season}

The time-course of recovery after fatiguing contractions in Palaemon serratus tail muscles was markedly influenced by season: recovery of phosphometabolite concentrations as well as intracellular $\mathrm{pH}$ proceeded faster in summer, when the rate of glycolysis was lower. In winter, restoration of the pre-exercise values must include anaerobic processes, since muscle $\mathrm{pH}$ decreases during recovery.

Therefore, seasonal variations must be taken into account when studying muscular energy metabolism in ectothermic animals. During environmental conditions of low temperature, the energetic stores of the muscle are greatly affected, which will lead to dramatic reduction of performance.

\section{LITERATURE CITED}

Alderdice, D. F. (1972). Responses of marine poikilotherms to environmental factors acting in concert. In: Kinne, $\mathrm{O}$. (ed.) Marine ecology, Vol. I, Part 3. Wiley, London, p. 1659-1722

Atkinson, D. E. (1977). Cellular energy metabolism and its regulation. Academic Press, New York

Blomstrand, E., Essén-Gustavsson, B. (1987). Influence of reduced muscle temperature on metabolism in type $I$ and type II human muscle fibres during intensive exercise. Acta Physiol. Scand. 131: 569-574

Chapman, A. G., Fall, L., Atkinson, D. E. (1971). Adenylate energy charge in Escherichia coli during growth and starvation. J. Bacteriol. 108: 1072-1086

Chen, S. C., Brown, P. R., Rosie, D. M. (1977). Extraction procedures for use prior to HPLC nucleotide analysis using microparticle chemically bonded packings. J. Chromatogr. Sci. 15: 218-221

Cole, H. A. (1958). Notes on the biology of the common prawn Palaemon serratus (Pennant). Fisheries Invest. Lond. Ser. 22: $1-22$

Collatz, K. G. (1973). Temperature-dependent storage processes in crayfish and spiders. In: Wieser, W. (ed.) Effects of temperature on ectothermic organisms. Springer-Verlag, Berlin, p. 195-199

Dawson, M. J., Gadian, D. G., Wilkie, D. R. (1977). Contraction and recovery of living muscles studied by ${ }^{31} \mathrm{P}$ nuclear magnetic resonance. J. Physiol. Lond. 267: 703-735

Giesy, J. P., Dickson, G. W (1981). The effect of season and location on phosphoadenylate concentrations and adenylate energy charge in two species of freshwater clams. Oecologia (Berl.) 49: 1-7

Heisler, N., Weitz, H., Weitz, A. M. (1976). Extracellular and intracellular $\mathrm{pH}$ with changes of temperature in the dogfish Scyliorhinus stellans. Respir. Physiol. 26: 249-263

Jacobs, J. R., Atwood, H. L. (1981). Long-term facilitation of tension in crustacean muscle and its modulation by tem-

This article was submitted to the editor perature, activity and circulatory amines. J. comp. Physiol. 144: $335-343$

Johnston, I. A., Eddy, F. B., Maloiy, G. M. O. (1983). The effects of temperature on muscle $\mathrm{pH}$, adenylate and phosphagen concentrations in Oreochromis alcalicus grahami, a fish adapted to an alkaline hot-spring. J. Fish Biol. 23: 717-724

Khym, J. X. (1975). An analytical systen for rapid separation of tissue nucleotides at low pressures on conventional anion exchangers. Clin. Chem. 21. 1245-1252

Koehn, R. K., Bayne, B. L. (1989). Towards a physiological and genetical understanding of the energetics of the stress response. Biol. J. Linn. Soc. 37: 157-171

Lavanchy, N., Martin, J., Rossi, A. (1985). Caractérisation par la spectroscopie en RMN du ${ }^{31} \mathrm{P}$, de l'état du métabolisme énergétique cardiaque: comparaison avec les données biochimiques. J. Physiol., Paris 80: 196-201

Malan, A., Wilson, T. L., Reeves, R. B. (1976). Intracellular pH in cold-blooded vertebrates as a function of body temperature. Respir. Physiol. 28: 29-47

McLeese, D. W., Wilder, D. G. (1958). The activity and catchability of the lobster (Homarus americanus) in relation to temperature. J. Fish. Res. Bd Can. 15: 1345-1354

Ohira, M. Ohira, Y (1988). Effects of exposure to cold on metabolic characteristics in gastrocnemius muscle of frog (Rana pipiens). J. Physiol., Lond. 395: 589-595

Raffin, J. P., Thébault, M. T (1987). Purification and partial characterization of an AMP deaminase from the marine invertebrate Palaemon serratus. Comp. Biochem. Physiol. 88B: $1071-1076$

Raffin, J. P., Thébault, M. T., LeGall, J. Y (1988). Changes in phosphometabolite and intracellular $\mathrm{pH}$ in the tail muscle of the prawn Palaemon serratus as shown by in vivo ${ }^{31} \mathrm{P}$ NMR. J. Comp. Physiol. B 158: 223-228

Reed, E. B. (1976). Coordination of adenylate energy charge and phosphorylation state during ischemia and under physiological conditions in rat liver and kidney. Life Sci. 19: $1307-1322$

Richard, P. (1978). Tolérance aux températures extrêmes de Palaemon serratus (Pennant): influence de la taille et de l'a cclimatation. J. exp. mar. Biol. Ecol. 35: 137-146

Sahlin, K., Edström, L., Sjöholm, H. (1983). Fatigue and phosphocreatine depletion during carbon dioxide-induced acidosis in rat muscle. Am. J. Physiol. 245: C15-C20

Somero, G. N., Hochachka, P. W. (1976). Biochemical adaptation to temperature. In: Newell, R. C. (ed.) Adaptation to environment: essays on the physiology of marine animals. Butterworth, London, p. 125-190

Stephens, P. J. (1985). The effects of temperature and acclimation on crustacean nerve-muscle physiology. Biol. Bull. mar. biol. Lab., Woods Hole 169: 92-105

Thébault, M. T., Raffin, J. P., LeGall, J. Y. (1987). In vivo ${ }^{31} \mathrm{P}$ NMR in crustacean muscles: fatigue and recovery in the tail musculature from the prawn Palaemon elegans. Biochem. Biophys. Res. Commun. 145: 453-459

Thébault, M. T., Raffin, J. P. (1989). Use of in vivo ${ }^{31}$ P NMR in ecophysiological studies: evaluation of the energetic state in crustacean tail muscles. Oceanis 15: 489-498

Walsh, P. J., Moon, $\Upsilon$ W. (1982). The influence of temperature on extracellular and intracellular pH in the american eel, Anguilla rostrata (Le Sueur). Resp. Physiol. 50: 129-140

Manuscript first received: October 29, 1990

Revised version accepted: June 7, 1991 